\title{
Status of thiocyanate levels in the serum and saliva of non-smokers, ex-smokers and smokers
}

\author{
Ananya Madiyal ${ }^{1}$, Vidya Ajila ${ }^{1}$, Subhas G Babu${ }^{1}$, Shruthi Hegde ${ }^{1}$, Suchetha Kumari ${ }^{2}$, \\ Medhini Madi ${ }^{3}$, Sonika Achalli ${ }^{1}$, Priyadharshini Alva ${ }^{4}$, Harshini Ullal ${ }^{2}$
}

1. A. B. Shetty Memorial Institute of Dental Sciences, Nitte deemed to be University, Oral. Medicine and Radiology.

2. K. S. Hegde Medical Academy, Nitte deemed to be University, Biochemistry.

3. Manipal College of Dental sciences, Manipal, Oral Medicine and Radiology.

4. Oral Medicine and Radiology Specialist.

\section{Emails:}

1. Ananya Madiyal- Email id: ananyamadiyal@gmail.com, 2. Vidya Ajila-Email id: ajila_v@yahoo.com, 3. Subhas G Babu-Email id: goginenisb@yahoo.co.in, 4. Shruthi Hegde-Email id: drshruthihegde@yahoo.co.in, 5. Sucheta Kumari-Email id: kumari.suchetha@gmail.com,6. Medhini Madi-Email id:medhkat@gmail.com, 7. Sonika Achalli-Email id: sonikachalli@gmail. com, 8. Priyadharshini Alva-Email id: alva.priya@gmail.com, 9. Harshini Ullal-Email id: ullalharshini@gmail.com

\begin{abstract}
Background: Use of tobacco is often implicated in the development of oral diseases. Questionable accuracy of the traditional questionnaires to assess cigarette exposure necessitates the use of biomarkers like thiocyanate which provide a definitive quantitative measure.

Objective: To assess the rise in the level of thiocyanate for measurement of smoking behaviour in adults.

Materials and methods: Serum and salivary thiocyanate levels were estimated in 20 non-smokers, 20 ex-smokers and 40 smokers. Smokers were divided into two groups based on the presence or absence of oral mucosal lesions.

Results: The mean serum and salivary thiocyanate levels were increased significantly in smokers when compared to non-smokers and ex-smokers. The levels were not significantly different between ex-smokers and non-smokers and between smokers with tobacco related oral mucosal lesions and those without. Statistically significant correlation was seen between the serum and salivary levels of thiocyanate.

Conclusion: This study highlights the high level of thiocyanate in the serum and saliva of smokers when compared to non-smokers and ex-smokers. Significant increase in thiocyanate level was also seen in saliva. Hence it can be stated that saliva can be used as a reliable, non-invasive tool to assess smoking behaviour in the population and its changes over time.
\end{abstract}

Keywords: Thiocyanate, Tobacco, Smoking, Cancer, Pre-cancer.

DOI: https://dx.doi.org/10.4314/ahs.v18i3.31

Cite as: Madiyal A, Ajila V, Babu SG, Hegde S, Kumari S, Madi M, Achalli S, Alva P, Ullal H. Status of thiocyanate levels in the serum and saliva of non-smokers, ex-smokers and smokers. Afri Health Sci. 2018;18(3): 727-736. https://dx.doi.org/10.4314/abs.v18i3.31

\section{Corresponding author:}

Ananya Madiyal, Department of Oral Medicine and Radiology

A. B Shetty Memorial Institute of Dental Sciences

Nitte deemed to be University

Deralakatte, Mangalore-575018

Contact number: +919538840189

Email: ananyamadiyal@gmail.com

\section{Introduction}

Tobacco use is one of the greatest challenges that is faced by the global healthcare today. Approximately 33\% of the adult population consumes tobacco in one form or the other. ${ }^{1}$ Risk factors such as use of tobacco products, alcohol consumption, betel nut chewing and human papilloma virus have been linked to the development of lesions like smoker's palate, leukoplakia, erythroplakia, oral submucous fibrosis and erosive lichen planus. These 
potentially malignant disorders along with oral carcinomas cause significant morbidity and mortality in patients. Oral cancer is one of the leading causes of death in India with incidence rates standing at 53842 cases in males and 23161 cases in females., ${ }^{2,3}$ As there exists a long time lapse between the use of tobacco and the appearance of disease, the effect of today's globalization of tobacco market will be felt for decades to come. ${ }^{1}$

Tobacco diminishes quality of life, beginning with things as modest as halitosis to as intricate as developmental abnormalities in children whose mothers were smokers during pregnancy. Tobacco is known to decrease the body's immune response and is a well-known cause for the development of adult periodontitis, oral cancer and oral cancer recurrence. ${ }^{1}$ The use of tobacco has been positively linked to the development of leukoplakia and oral submucous fibrosis which have a potential for malignant transformation.3 It is seen that there exists a clear dose-response relationship between smoking and oral cancer. Some studies show that, after a decade of quitting, the risk of development of cancer was the same as that of non-smokers while other studies found that the risk in ex-smokers was marginally increased. ${ }^{4,5}$

Traditionally, measurement of exposure to cigarettes has been done through questionnaires. The exactness of such a method is limited due to cognizant false reporting as well as insufficient recognition of the true degree of exposure. 6 To overcome this hurdle, various biochemical markers of cigarette smoke like carbon monoxide, nicotine, cotinine and thiocyanate have been used as measures of smoking behaviour in the recent years. ${ }^{6}$ The long biologic half-life of thiocyanate (10-14 days) makes it an ideal substrate to determine habitual smoking behaviour. ${ }^{7}$ The combustion of nitrogen containing compounds found in cigarettes leads to inhalation of hydrogen cyanide $(\mathrm{HCN})$ gas which is ultimately assimilated into the body as cyanide (CN-). This inhibits the activity of cytochrome oxidase. ${ }^{8}$ Cyanide is gradually released from its bond with ferric ion and is metabolized to thiocyanate after accepting a sulfur atom from a sulfur donor such as thiosulfate. This reaction is catalyzed by thiosulfate transferase. ${ }^{9}$ The thiocyanate level in plasma is considered to be a good indicator of exposure to cyano-containing organic substances since thiocyanate levels are inexorably high when the plasma cyanide levels are high. ${ }^{9}$ Saliva also shows high levels of thiocyanate and the physiologic role of thiocyanate in saliva maybe due to hypothiocyanate (HOSCN) which produces an antibacterial effect by the action of salivary peroxides. ${ }^{8}$

With the current study we aimed to measure the level of thiocyanate in the serum and saliva of non-smokers, ex-smokers and smokers to determine its efficacy as a biochemical marker of smoking behaviour.

\section{Materials and methods}

The present study was an observational study conducted on subjects reporting to the Department of Oral Medicine and Radiology at a Dental Science Institute in South India. The sample population consisted of semi-urban and rural subjects.

Sample size was determined based on the pilot study performed. A sample of 17.5 was determined as the minimum in each group to estimate and to calculate for the statistical analysis. We rounded 17.5 into 20 so as to reduce errors. Therefore, the study sample included a total of 80 subjects who were divided into the following groups:

Control Group (C): 20 subjects who were non-smokers of tobacco products.

Group I (G1): 20 subjects who were ex-smokers of tobacco products.

Group II (G2): 40 subjects who were smokers of tobacco products.

Sub-Group IIa (G2a): 20 subjects who were smokers of tobacco products without oral mucosal lesions associated with any tobacco related disorders.

Sub-Group IIb (G2b): 20 subjects who were smokers of tobacco products with oral mucosal lesions associated with tobacco related disorders.

Strict inclusion criteria were followed for the control group and the study groups. Healthy non-smoker subjects in the age group of 18-60 years, without any history of oral and systemic diseases were taken as controls. Group I consisted of subjects who were in the age group of 18-60 years who used to smoke one or more than one pack of hand rolled or manufactured tobacco products per day but had quit since the last 1 year. Group II consisted of subjects who were in the same age group who regularly smoked one or more than one pack of hand 
rolled or manufactured tobacco products per day since the last 1 year or more. This group was subdivided into GIIa consisting of subjects who did not present with oral mucosal lesions associated with any tobacco related disorders. GIIb consisted of subjects who presented with oral mucosal lesions associated with tobacco related disorders including, but not restricted to, leukoplakia, erythroplakia, stomatitis nicotina, smoker's melanosis and oral squamous cell carcinoma.

Subjects with a history of any long term systemic diseases or acute infections, subjects who were on any medications like erythromycin, nitroprusside, chlorambucil, ifosfamide and melphalan, and subjects with a positive history of tobacco chewing habits were excluded from the study. Each patient was thoroughly examined both intra orally and extra orally under artificial illumination.

\section{Method of collection of data Sample collection:}

Informed consent was obtained from the patients included in the study. Ethical clearance was obtained from the Institutional Ethical Committee. Detailed case history was recorded along with thorough examination of the oral cavity. Collection of serum and saliva was done between 9 a.m and 12 p.m to minimize possible diurnal variations in sampling.

\section{Saliva collection:}

All salivary samples were collected from patients 2 hours after food using spit technique. The patient was asked to sit in the dental chair with the head tilted forward and instructed not to speak or swallow any saliva. Then the patient was instructed to spit into a sterile graduated container every minute for 5-8 minutes. Salivary sample represented whole mouth fluid. The collected sample was centrifuged at $3000 \mathrm{rpm}$ for 10 minutes and the supernatant was collected and stored at $-20^{\circ} \mathrm{C}$.

\section{Blood collection:}

$5 \mathrm{ml}$ of venous blood was collected from the antecubital vein with syringe and placed in vials. Serum was then extracted and stored at temperature of $-4^{\circ} \mathrm{C}$ in glass vials.

\section{Reagents used:}

- Bromine water, saturated

- Arsenious oxide

- $20 \mathrm{~g}$ of As2O3 per litre of 0.1 molar $\mathrm{NaOH}$, titrated to neutral (phenolphthalein endpoint)
- p-phenylenediamine

- $2 \mathrm{~g} /$ liter of 0.5 molar $\mathrm{HCl}$

- Pyridine reagent

- Pyridine-concentrated HCl-de-ionized water, 6:1:4 by volume

- Pyridine-p-phenylenediamine reagent

- Pyridine reagent-p-phenylenediamine reagent, 3:1 by volume

\section{Procedure}

\section{Estimation of thiocyanate in serum or saliva:}

Serum (1 ml) was separated and de-proteinized by adding trichloroacetic acid ( $9 \mathrm{ml}$ of a $10 \mathrm{~g} / 100 \mathrm{ml}$ solution).

Portions $(1 \mathrm{ml})$ of the supernatant fluid were then analyzed for thiocyanate.

A portion $(1 \mathrm{ml})$ of the test solution (serum or saliva) was acidified $(0.5 \mathrm{ml}$ of $1 \mathrm{~mol} /$ litre $\mathrm{HCl})$ and bromine water was added ( 2 drops of saturated solution), followed, after mixing, by the addition of arsenious oxide solution (3 drops) to remove excess bromine.

Any traces of free bromine remaining were removed under reduced pressure.

The pyridine-p-phenylenediamine reagent $(1.8 \mathrm{ml})$ was then added and the absorbance of the resultant reddish-pink dyestuff was read against a reagent blank, the readings being taken within $10 \mathrm{~mm}$ at a wavelength known to be isosbestic point for this reaction.

This wavelength was determined by examination of the color reaction in a recording spectrophotometer and was generally found at $520 \mathrm{~nm}$. The absorbance so obtained was plotted against a graph to get the thiocyanate concentration. The optical density of the pink color formed was directly proportional to the thiocyanate concentration in the sample.

\section{Calculation}

Direct proportionality was observed between the optical density of the test samples and thiocyanate concentration. Calculation was done by plotting against the standard graph with the $\mathrm{X}$-axis showing thiocyanate and Y-axis showing the optical density. It was multiplied by the respective dilution factors and the final concentration was expressed as $\mu \mathrm{M} / 1$.

\section{Statistical analysis}

The data obtained from study was analyzed using SPSS version 17.0 software. One way ANOVA test was used 
for analysis of thiocyanate levels in all groups. Posthoc Tukey's test was used for the comparison of Study Groups to the Control Group and the Study Groups with each other. Student's T test was used for comparison between smokers with and without oral mucosal lesions associated with tobacco related disorders. Pearson's Co-relation Co-efficient was used to correlate the changes in the levels of serum and salivary thiocyanate levels between the Study Groups and the Control Group and the Study Groups with each other. $\mathrm{P}<0.05$ was considered significant.

\section{Results}

\section{Demographic data analysis of the groups}

The age range of subjects was 19-60 years in Group C as well as in Group II while it was 19-58 years in Group I.
All the groups consisted of only male subjects. The mean age in Group C was $41.9 \pm 14.51$ years while in Group I and Group II were $44.35 \pm 13.84$ years and $43.7 \pm 12.87$ years respectively.

Among the 20 smokers who showed the presence of oral mucosal lesions associated with tobacco related disorders, 9 subjects had smoker's melanosis, 5 had oral homogeneous leukoplakia, 3 had oral cancer and 3 had smoker's palate.

Analysis of mean serum and salivary thiocyanate levels in non-smokers, ex-smokers and smokers Mean serum thiocyanate levels

The mean serum thiocyanate levels in Group C was 58.67 $\pm 2.48 \mu \mathrm{M} / 1$ while the mean serum thiocyanate levels of Group I and Group II were $58.47 \pm 2.67 \mu \mathrm{M} / 1$ and $142.71 \pm 3.05 \mu \mathrm{M} / 1$ respectively. (Table 1 , Figure 1 )

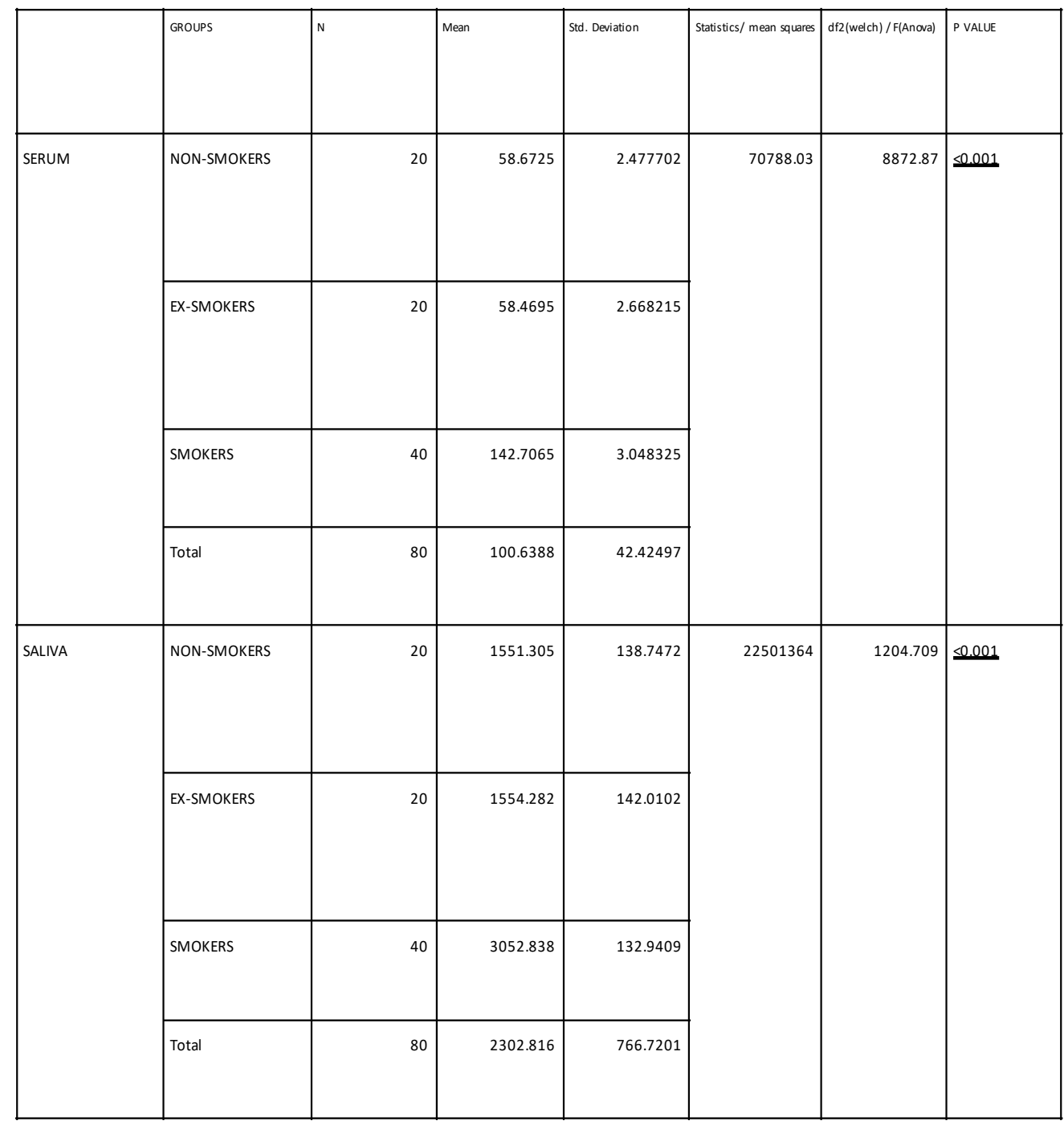

TABLE 1: Comparison of serum and salivary levels of thiocyanate using one way ANOVA 


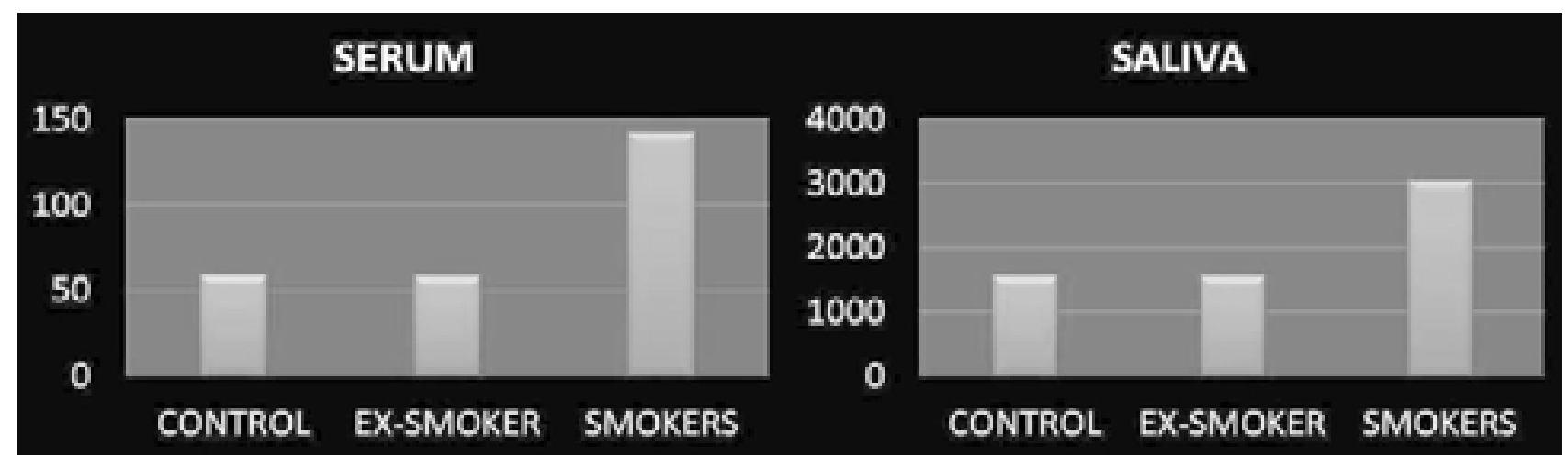

Figure 1: Graphs showing mean serum and salivary thiocyanate levels in non-smokers, ex-smokers and smokers.

Mean salivary thiocyanate levels:

The mean salivary thiocyanate levels in Group C was $1551.305 \pm 138.75 \mu \mathrm{M} / 1$, while the mean salivary thiocyanate levels of Group I and Group II were $1554.282 \pm$ $142.01 \mu \mathrm{M} / 1$ and $3052.838 \pm 132.94 \mu \mathrm{M} / 1$ respectively. (Table 1, Figure 1)

Analysis of statistical significance

Serum thiocyanate levels:

When serum levels of thiocyanate were compared be- tween Group C $(58.67 \pm 2.48 \mu \mathrm{M} / \mathrm{l})$ and Group I (58.47 $\pm 2.67 \mu \mathrm{M} / \mathrm{l})$, the difference was not statistically significant $(p=0.972)$. When the serum levels of thiocyanate in Group C was compared with Group II (142.71 $\pm 3.05 \mu \mathrm{M} / \mathrm{l})$, highly significant difference was obtained $(p<0.001)$. Statistical comparison of serum levels of thiocyanate between Group I and Group II again showed highly significant difference $(\mathrm{p}<0.001)$. (Table 2$)$

Table 2: Comparison of serum and salivary levels of thiocyanate among group $\mathrm{C}$, group I and group II using Posthoc Tukey test

\begin{tabular}{|c|c|c|c|c|c|}
\hline $\begin{array}{l}\text { Dependent } \\
\text { Variable }\end{array}$ & (I) group & (J) group & $\begin{array}{l}\text { Mean Difference } \\
(\mathrm{I}-\mathrm{J})\end{array}$ & $\begin{array}{l}\text { Std. } \\
\text { Error }\end{array}$ & $\begin{array}{l}P \\
\text { Value }\end{array}$ \\
\hline \multirow[t]{3}{*}{ Serum } & \multirow[t]{2}{*}{$\begin{array}{l}\text { Non- } \\
\text { smokers }\end{array}$} & $\begin{array}{l}\text { Ex- } \\
\text { smokers }\end{array}$ & 0.203 & 0.893198 & 0.972 \\
\hline & & Smokers & $-84.0340000^{*}$ & 0.773532 & $<0.001$ \\
\hline & $\begin{array}{l}\text { Ex- } \\
\text { smokers }\end{array}$ & Smokers & $-84.2370000^{*}$ & 0.773532 & $<0.001$ \\
\hline \multirow[t]{3}{*}{ Saliva } & \multirow[t]{2}{*}{$\begin{array}{l}\text { Non- } \\
\text { smokers }\end{array}$} & $\begin{array}{l}\text { Ex- } \\
\text { smokers }\end{array}$ & -2.977 & 43.21787 & 0.997 \\
\hline & & Smokers & $-1501.5325000^{*}$ & 37.42778 & $<0.001$ \\
\hline & $\begin{array}{l}\text { Ex- } \\
\text { smokers }\end{array}$ & Smokers & $-1498.5555000^{*}$ & 37.42778 & $<0.001$ \\
\hline
\end{tabular}

Salivary thiocyanate levels:

When salivary levels of thiocyanate were compared between Group C $(1551.305 \pm 138.75 \mu \mathrm{M} / \mathrm{l})$ and Group $\mathrm{I}(1554.282 \pm 142.01 \mu \mathrm{M} / \mathrm{l})$, the difference was not statistically significant $(p=0.997)$. When the salivary levels of thiocyanate in Group C was compared with Group II $(3052.838 \pm 132.94 \mu \mathrm{M} / \mathrm{l})$, highly significant difference was obtained $(p<0.001)$. Statistical comparison of sali- vary levels of thiocyanate between Group I and Group II showed highly significant difference $(\mathrm{p}<0.001)$. (Table 2$)$ Serum and salivary thiocyanate between Group IIa and Group IIb $(142.733 \pm 2.99 \mu \mathrm{M} / 1 ; 142.68 \pm 3.18 \mu \mathrm{M} / 1$ and $3056.899 \pm 128.42 \mu \mathrm{M} / \mathrm{l} ; 3048.777 \pm 140.53 \mu \mathrm{M} / \mathrm{l})$ were compared using Student's T-Test. The differences were not statistically significant $(\mathrm{p}=0.957$ and $\mathrm{p}=0.85)$. (Table 3) 
Table 3: Comparison of serum and salivary levels of thiocyanate among smokers with and without oral mucosal lesions associated with tobacco related disorders using T-Test

\begin{tabular}{|l|l|l|l|l|l|l|r|}
\hline & Group & N & Mean & $\begin{array}{l}\text { Std. } \\
\text { Deviation }\end{array}$ & $\mathbf{t}$ & df & p VALUE \\
\hline \multirow{2}{*}{ Serum } & $\begin{array}{l}\text { Smokers with oral mucosal } \\
\text { lesions associated with } \\
\text { tobacco related disorders }\end{array}$ & 20 & 142.68 & 3.183973 & & & \\
\cline { 2 - 6 } & $\begin{array}{l}\text { Smokers without oral } \\
\text { mucosal lesions associated } \\
\text { with tobacco related disorders }\end{array}$ & 20 & 142.733 & 2.989059 & -0.054 & 38 & 0.957 \\
\multirow{2}{*}{ Saliva } & $\begin{array}{l}\text { Smokers with oral mucosal } \\
\text { lesions associated with } \\
\text { tobacco related disorders }\end{array}$ & 20 & 3048.777 & 140.5342 & & & \\
\cline { 2 - 5 } & $\begin{array}{l}\text { Smokers without oral } \\
\text { mucosal lesions associated } \\
\text { with tobacco related disorders }\end{array}$ & 20 & 3056.899 & 128.4217 & -0.191 & 38 & 0.85 \\
\hline
\end{tabular}

Correlation of serum thiocyanate with salivary thiocyanate levels among the groups

Pearson's Correlation coefficient was used to correlate the serum and salivary thiocyanate between the groups. Excellent correlation was observed between the level of thiocyanate in the serum and saliva in Group $\mathrm{C}(\mathrm{r}=$ 0.954) (Table 4, Figure 2), Group I ( $\mathrm{r}=0.947$ ) (Table 4, Figure 2), Group II ( $r=0.967)$ (Table 4, Figure 2), Group $\mathrm{IIa}(\mathrm{r}=0.977)$ (Table 5, Figure 3) and Group IIb $(\mathrm{r}=0$. .959) (Table 5, Figure 3).
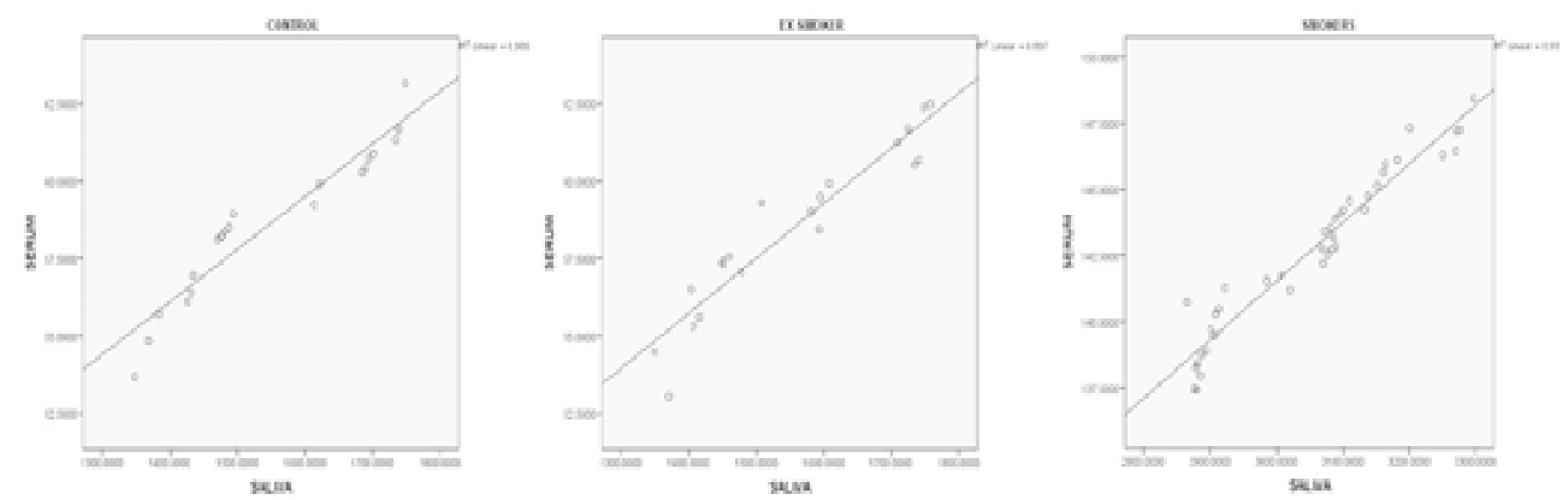

Figure 2: Correlation of serum and salivary thiocyanate levels using Pearsons correlation (Group C. Group I, Group II). 

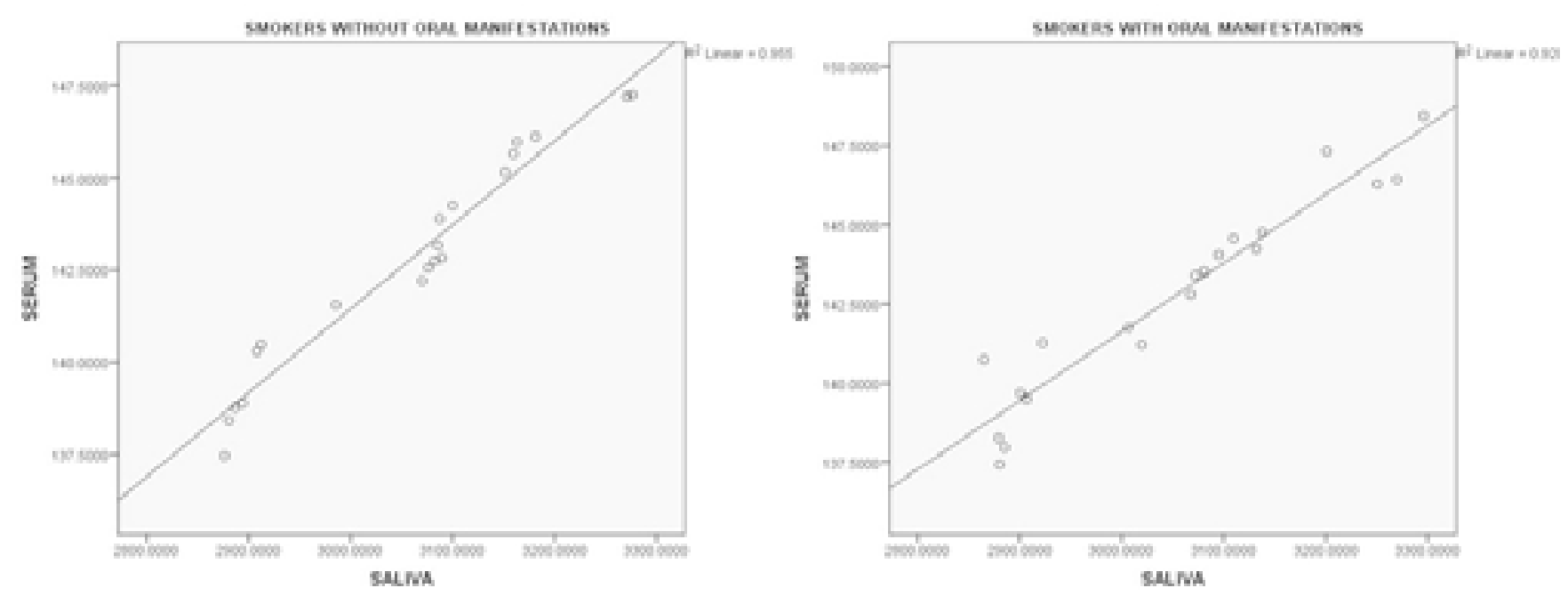

Figure 3: Correlation of serum and salivary thiocyanate levels using Pearsons correlation (Group IIa, Group IIb).

Table 4: Correlation of serum and salivary levels of thiocyanate among non-smokers, ex-smokers and smokers using Pearsons correlation

\begin{tabular}{|c|c|c|c|}
\hline Correlations & & & \\
\hline Group & & Serum & \\
\hline Non-smokers & Saliva & $\begin{array}{l}\text { Pearson } \\
\text { Correlation }\end{array}$ & .954 \\
\hline & & Sig. (2-tailed) & $<0.001$ \\
\hline & & $\mathrm{N}$ & 20 \\
\hline Ex-smokers & Saliva & $\begin{array}{l}\text { Pearson } \\
\text { Correlation }\end{array}$ & .947 \\
\hline & & Sig. (2-tailed) & $<0.001$ \\
\hline & & $\mathrm{N}$ & 20 \\
\hline Smokers & Saliva & $\begin{array}{l}\text { Pearson } \\
\text { Correlation }\end{array}$ & .967 \\
\hline & & Sig. (2-tailed) & $<0.001$ \\
\hline & & $\mathrm{N}$ & 40 \\
\hline
\end{tabular}

Table 5: Correlation of serum and salivary levels of thiocyanate among smokers with and without oral mucosal lesions associated with tobacco related disorders using Pearsons correlation

\begin{tabular}{|l|l|r|r|}
\hline \multicolumn{1}{|c|}{ Correlations } & \multicolumn{3}{|l|}{ Serum } \\
\hline Group & Saliva & $\begin{array}{l}\text { Pearson } \\
\text { Correlation }\end{array}$ & .977 \\
\hline $\begin{array}{l}\text { Smokers without } \\
\text { oral mucosal lesions } \\
\text { associated with tobacco } \\
\text { related disorders }\end{array}$ & & Sig. (2-tailed) & $<\mathbf{0 . 0 0 1}$ \\
\hline $\begin{array}{l}\text { Smokers with } \\
\text { oral mucosal lesions } \\
\text { associated with tobacco } \\
\text { related disorders }\end{array}$ & Saliva & $\begin{array}{l}\text { Pearson } \\
\text { Correlation }\end{array}$ & .959 \\
\hline & & Sig. (2-tailed) & $<0.001$ \\
\hline
\end{tabular}




\section{Discussion}

The harmful effects of smoking on oral health are well established. Smoking affects both the adoptive and innate arms of the immune system. It augments pro-inflammatory cytokine production and reduces the anti-inflammatory cytokine levels thereby leading to the disease process. ${ }^{10}$ It has been linked to the etiology of oral cancer, pre-cancer, periodontitis, caries, tooth loss and other soft tissue changes. ${ }^{11}$

Although the levels of thiocyanate are known to increase tremendously on exposure to tobacco smoke, several other factors like industrial cyanide exposure and drugs like sodium nitroprusside cause serum thiocyanate levels to rise. Serum thiocyanate levels are also elevated on ingestion of certain food such as turnips, horseradish, the cabbage family, garlic, mustard, beer and almond. Here, 3-indolylglucothiocyantes are split by thioglucosidase into glucose and isothiocyanates. Isothiocyanates are then converted into thiocyanate by thiocyanate isomerase. ${ }^{6} \mathrm{Zil}-$ a-Rubab et al found that although thiocyanate levels do vary according to diet and atmospheric exposure, the levels in smokers far exceeded that of passive smokers and non-smokers. ${ }^{12}$ It has also been reported that alimentary sources such as cyanogenic food do not affect thiocyanate levels in the saliva. ${ }^{8}$ Therefore a significant increase in thiocyanate levels can be considered to be specific to smoking habit while the thiocyanate in blood is mainly distributed in the serum and its presence indicates detoxification of cyanide from a more varied source. ${ }^{12}$ Thus salivary thiocyanate level could be used as a determinant of regularsmoking patterns.

In the current study, the mean serum as well as salivary thiocyanate levels of smokers were more than twice that of non-smokers. This was in accordance with the study by Vogt et al who stated that the rise in serum thiocyanate level in smokers was due to the minute amounts of cyanide present in the tobacco smoke. ${ }^{6}$ Thus it can be inferred that the two-week biologic half-life of thiocyanate makes it an ideal substrate to measure habitual smoking behaviour.

It was observed in the present study that there was no correlation between the age of study subjects and their serum and salivary thiocyanate levels which is in accordance with the study by Tsuge et $\mathrm{al}^{8}$ who found that although smokers showed higher levels of thiocyanate in their serum and saliva in comparison with non-smokers, there was no correlation between the age of the subjects and the thiocyanate levels. It was seen that all subjects in the study were males which can be attributed to the social constraints of the rural and semi urban study population included in the study.

In the present study, the mean serum thiocyanate level in ex-smokers was $58.47 \pm 2.67 \mu \mathrm{M} / 1$ which was markedly decreased when compared to the level in smokers. This is a unique feature of this study as, to the best of our knowledge, we did not find any report in existing literature where the serum thiocyanate level was measured in ex-smokers. Thus quantification of thiocyanate level in the serum can be used as a measure of extent of compliance in tobacco cessation practices.

There exists a statistically significant difference between the levels of salivary thiocyanate in non-smokers and smokers as well as between ex-smokers and smokers. But the difference was not statistically significant between non-smokers and ex-smokers. This is in accordance with the study conducted by Luepker et $\mathrm{al}^{13}$ who found that salivary thiocyanate levels increased in smokers but not in non-smokers, light smokers and self-declared 'quit' smokers. Thus the elevated salivary thiocyanate level could be associated with regular cigarette use which thereby determined the smoking patterns.

In the present study, the mean serum and salivary thiocyanate level in ex-smokers was markedly decreased when compared to smokers. Thus quantification of thiocyanate level can be used as a measure of compliance to tobacco cessation practices. The present study showed excellent positive correlation between the serum and salivary levels of thiocyanate in all the study groups and also showed that the salivary values were higher than the serum values. Degiampietro et $\mathrm{al}^{14}$ also found that the concentration of thiocyanate in parotid saliva as well as whole saliva was approximately thirty times higher than the level in plasma. Thus it could be hypothesized that thiocyanate must accumulate in the parotid gland and is then secreted through a process which is yet undetermined. 
Smoking weakens humoral as well as cell mediated immune responses. There is a severe compromise in the oxygen uptake by polymorphonuclear cells (PMN) and production of oxygen radicals. This collectively leads to impairments in both the phagocytic as well as the chemotactic capability of leucocytes of smokers. ${ }^{15}$ This mechanism could contribute to various oral diseases in smokers.

In the present study, among the 20 smokers who demonstrated oral mucosal lesions, the highest prevalence was for smoker's melanosis followed by oral homogeneous leukoplakia. Oral cancer and smoker's palate were found next in the order. The presence of soft tissue lesions in tobacco users can be ascribed to the irritation caused by tobacco to the oral structures. Genetic and host factors such as dysregulation of adhesion molecule, reduced $\mathrm{T}$ cell antigen response, alteration in the neutrophil activity and platelet aggregation could also affect the immune system. ${ }^{16}$ However, the present study showed no statistically significant difference between the thiocyanate levels in the serum and saliva of smokers with and without tobacco associated oral mucosal lesions. This may be due to the cross-sectional design which was employed in the present study which may not indicate the true temporal relationship between thiocyanate levels and the development of oral mucosal lesions.

The biologic half-life of thiocyanate is 7-14 days., ${ }^{7,8}$ Therefore, in ex-smokers who have abstained from the habit, the level of thiocyanate gradually decreases to the level seen in non-smokers. Hence the inclusion of the ex-smoker group can be considered as another limitation of this study. However, we wanted to check for the possible role of thiocyanate in the development of oral mucosal lesions that are commonly found among smokers since thiocyanate decreases immune response and acts as a stimulant to pro-inflammatory mediators.

As significant increase of thiocyanate level is observed both in serum and saliva, this study suggests the use of thiocyanate as a potential biomarker for determining smoking behaviour in adults. In addition, an excellent positive correlation was observed between the thiocyanate levels in the serum and saliva thereby indicating that saliva could be a reliable and non-invasive tool indiagnosis, monitoring and management of oral mucosal lesions associated with tobacco related disorders.

\section{Conclusion}

The increase in serum and salivary levels of thiocyanate in smokers shows promise towards the use of thiocyanate to validate smoking behaviour. The determination of thiocyanate levels in ex-smokers can help establish thiocyanate as a potential biomarker in tobacco cessation studies, to investigate the authenticity of self-reported smoking behaviour and to confirm the absorption of specific smoke constituents in a quantitative manner. These informative biomarkers can further serve as early sentinels of disease and have been considered as the most promising alternative to existing epidemiological data.

Saliva can be considered as the mirror of the body's health. Thus the findings of the present study indicate that estimation of thiocyanate could determine the smoking behaviour by using saliva, which is augmented by the ease of its collection and its non-invasive nature.

\section{Conflict of interest}

The authors declare that there is no conflict of interest.

\section{References}

1. Petersen PE. Tobacco and oral health- Role of world health organization. Oral Health Prev Dent. 2003; 1:309-15. PubMed. [doi: 10.1046/j.1600-0528.2003.00124.x]

2. Varshitha A. Prevalence of Oral Cancer in India. $J$ Pharm Sci Res. 2015; 7(10): 845-8. PubMed.

3. Sridharan G. Epidemiology, control and prevention of tobacco induced oral mucosal lesions in India. Indian J Cancer. 2014; 51:80-5 PubMed. [doi: 10.4103/0019509x.134651]

4. Blot WJ, McLaughlin JK, Winn DM, Austin DF, Greenberg RS, Preston-Martin S, Bernstein L, Schoenberg JB, Stemhagen A, Fraumeni JF Jr. Smoking and drinking in relation to oral and pharyngeal cancer. Cancer Res. 1988; 48:3282-7. PubMed. [PMID: 3365707]

5. Macfarlane GJ, Zheng T, Marshall JR, Boffetta P, Niu

S, Brasure J, Merletti F, Boyle P. Alcohol, tobacco, diet and the risk of oral cancer: A pooled analysis of three case-control studies. Eur J Cancer B Oral Oncol. 1995; 31B:181-7. [doi: 10.1016/0964-1955(95)00005-3]

6. Vogt TM, Selvin S, Widdowson G, Hulley SB. Expired air carbon monoxide and serum thiocyanate as objective measures of cigarette exposure. Am J Public Health. 1977; 67:545-9. PubMed. [doi: 10.2105/ajph.67.6.545]

7. Morgan PE, Pattison DI, Talib J, Summers FA, Harmer 
JA, Celermajer DS, Hawkins CL, Davies MJ. High plasma thiocyanate levels in smokers are a key determinant of thiol oxidation induced by myeloperoxidase. Free Radic Biol Med. 2011; 51:1815-22. PubMed. [doi: 10.1016/j.freeradbiomed.2011.08.008]

8. Tsuge K, Kataoka M, Seto Y. Cyanide and thiocyanate levels in blood and saliva of healthy adult volunteers. $J$ Health Sci. 2000; 46:343-50. PubMed. [doi: 10.1248/ jhs.46.343]

9. Lundquist P, Kagedal B, Nilsson L. An improved method for determination of thiocyanate in plasma and urine. Eur J Clin Chem Clin Biochem. 1995; 33:343-9. [doi: 10.1515/cclm.1995.33.6.343. PubMed.

10. Arnson Y, Shoenfeld Y, Amital H. Effects of tobacco smoke on immunity, inflammation and autoimmunity. J Autoimmun. 2010; 34:J258-J265. [doi: 10.1016/j. jaut.2009.12.003]

11. Kanehira T, Shibata K, Kashiwazaki H, Inoue N, Morita M. Comparison of antioxidant enzymes in saliva of elderly smokers and non-smokers. Gerodontology. 2006; 23:38-42. [doi: 10.1111/j.1741-2358.2006.00077.x]

12. Zil-a-Rubab, Rahman MA. Serum thiocyanate lev- els in smokers, passive smokers and never smokers. J Pak Med Assoc. 2006; 56:323-6 PubMed.

13. Luepker RV, Pechacek TF, Murray DM, Johnson CA, Hund F, Jacobs DR. Saliva thiocyanate: A chemical indicator of cigarette smoking in adolescents. Am J Public Health. 1981; 71:1320-4. PubMed. [doi: 10.2105/ ajph.71.12.1320]

14. Degiampietro P, Peheim E. Determination of thiocyanate in plasma and saliva without deproteinization and its validation s a smoking parameter. J Clin Chem Clin Biochem. 1987; 25; 711-17. [doi: 10.1515/cclm.1987.25.10.711. PubMed.

15. Pullishery F, Panchmal GS, Siddique S. Salivary thiocyanate, uric acid and $\mathrm{pH}$ as biomarkers of periodontal disease in tobacco users and non-users- an in-vitro study. J Clin Diagn Res. 2015; 9:ZC47-50. [doi: 10.7860/ jcdr/2015/12783.6203]

16. Al-Attas SA, Ibrahim SS, Amer HA, Darwish ZE, Hassan MH. Prevalence of Potentially Malignant Oral Mucosal Lesions among Tobacco Users in Jeddah, Saudi Arabia. Asian Pac J Cancer Prev. 2014; 15:757-62. [doi: 10.7314/apjcp.2014.15.2.757. PubMed. 